\title{
CONSEQÜÊNCIAS DO ATRASO NA ÉPOCA DE SEMEADURA E DE ENSILAGEM EM CARACTERÍSTICAS AGRONÔMICAS DO MILHO
}

\author{
TÁRIQUE EDUARDO ARECO VILLELA ${ }^{1}$ \\ RENZO GARCIA VON PINHO ${ }^{2}$ \\ MAXIMILIAN DE SOUZA GOMES ${ }^{3}$ \\ ANTÔNIO RICARDO EVANGELISTA ${ }^{4}$ \\ DENYS VÍTOR FERREIRA ${ }^{5}$
}

\begin{abstract}
RESUMO - Conduziu-se este estudo com o objetivo de avaliar as características agronômicas e o desempenho de cultivares de milho para silagem submetidas ao atraso nas épocas de semeadura e corte das plantas. Foram avaliadas nove cultivares de milho, em quatro experimentos instalados em duas épocas distintas, no ano agrícola 99/00, na área experimental da Universidade Federal de Lavras (UFLA-MG). Em cada época, foram conduzidos dois experimentos, e em um deles, as plantas foram cortadas quando a linha de leite apresentavase na metade do grão, e no outro, quando os grãos atingiram a maturidade fisiológica. Foram avaliadas as seguintes características: altura de plantas, produtividade de matéria seca total, rendimento de grãos, porcentagem de espigas, folhas e colmo na matéria seca total. Foi verificada a existência de variabilidade para a maioria das
\end{abstract}

características avaliadas, evidenciando a importância da escolha adequada das cultivares para a produção de silagem. A presença da interação cultivares x épocas de semeadura e cultivares $\mathrm{x}$ épocas de corte para a maioria das características avaliadas evidencia a importância dessa escolha em função da época de semeadura e de corte das plantas. As cultivares AG 1051, C 435 e AG 4051 são as que mais se destacaram para a produção de silagem. A maioria das características avaliadas foi influenciada pela época de semeadura e pela época de corte das plantas. $\mathrm{O}$ atraso na semeadura reduz significativamente a produção de matéria seca de silagem e a produtividade de grãos, e o inverso ocorre com o atraso na época de corte, obtem-se maior produtividade de matéria seca na maturidade fisiológica dos grãos.

TERMOS PARA INDEXAÇÃO: Zea mays, época de semeadura, época de corte, silagem.

\section{CONSEQUENCES OF THE DELAY IN THE SEASON OF SOWING AND SILAGE ON AGRONOMIC CHARACTERISTICS OF MAIZE}

\begin{abstract}
The objective of this work was to verify the effect of the delay in sowing and cutting seasons for silage on agronomic characteristics of maize cultivars. Nine cultivars of maize were evaluated in four experiments installed in two distinct seasons in the agricultural year 99/00, in the experimental area of the Federal University of Lavras (UFLA-MG). In each season, two experiments were conducted. In one of them, the plants were cut off when milk line laid on half of the grain and in the other experiment the harvest was
\end{abstract}

accomplished when grains reached physiological maturity. The following characteristics were evaluated plant height, dry matter and grain yield, percentage of ears in the dry matter, and percentage of leaves and stem in the dry matter. Variability was verified for most of the characteristics, pointing out the importance of an adequate choice of cultivars for silage production. The presence of interaction cultivars $\times$ sowing seasons and cultivars $\times$ cutting seasons for the most of the characteristics highlights the importance of

1. Engenheiro Agrônomo, Mestre em Agronomia/Fitotecnia, Lavras, MG, tariquevillela@hotmail.com

2. Professor, Dr. do Departamento de Agricultura da UNIVERSIDADE FEDERAL DE LAVRAS/UFLA, Caixa Postal 37 -37200-000, Lavras, MG, renzo@ufla.br

3. Engenheiro Agrônomo, Doutorando em Genética e Melhoramento de Plantas, Departamento de Biologia da UFLA, msgomes@ufla.br

4. Professor, Dr. do Departamento de Zootecnia da UFLA.

5. Aluno de Graduação do Curso de Engenharia Agronômica, Lavras, MG. 
cultivar selection in function of the sowing season and cutting season of the plants. In general, the cultivars AG 1051, C 435, and AG 4051 were the ones that stood out for silage production. Most of the evaluated characteristics were influenced by sowing season and cutting season. The delay in sowing reduced the production of dry matter of silage significantly and the inverse happened with delaying the cutting season, with larger productivity in the crop accomplished in the physiologic maturity of the grains.

INDEX TERMS: Zea mays, sowing season, cutting season, silage.

\section{INTRODUÇÃO}

A região sul de Minas Gerais caracteriza-se por ser uma importante bacia leiteira no Estado. Nessa região, o inverno é seco e há necessidade de complementar a alimentação dos rebanhos leiteiros. Por isso, grande parte da área cultivada com milho é destinada à produção de silagem de milho.

Embora a época recomendada para a semeadura do milho, nessa região, seja de 15 de outubro a 15 de novembro, tem-se constatado que a semeadura é postergada até janeiro, principalmente para a produção de silagem. Pela diversidade climática durante o período em que o milho é cultivado, é esperado efeito pronunciado da época de semeadura no crescimento e desenvolvimento da planta, podendo causar reflexos na produtividade de forragem.

Tem sido demonstrado que vários fatores ambientais afetam a produtividade e a qualidade da matéria seca do milho. Coors et al. (1994) observaram que temperaturas elevadas, embora contribuam para aumentar a porcentagem ou teor de matéria seca, reduzem a sua digestibilidade e a da parede celular. Alta intensidade luminosa afeta positivamente a produtividade de matéria seca e a digestibilidade. Já a semeadura e a colheita tardia contribuem para reduzir a produtividade e a digestibilidade da matéria seca na forragem de milho.

No caso da produção de matéria seca de forragem, Gonçalves et al. (1996) e Ramalho (1999) mostraram que o efeito do atraso da semeadura na produção de massa seca é similar ao da produção de grãos, já que foi detectada uma alta correlação entre a expressividade dessas duas características.

Oliveira et al. (1991), avaliando três cultivares em cinco épocas de semeadura, verificaram um decréscimo acentuado com o atraso da semeadura com relação principalmente à produtividade dos grãos. Ficou constatado também que a interação épocas $\mathrm{x}$ cultivares foi significativa, ao passo que a interação locais $\mathrm{x}$ cultivares não foi significativa, concluindo, assim, ser mais eficiente avaliar as cultivares de milho em experimentos conduzidos em maior número de épocas, em detrimento de locais.
A posição da "linha de leite" no grão tem sido recomendada como um ótimo parâmetro para determinar o ponto de colheita do milho para silagem. Estudos realizados por Sulc et al. (1996), para determinar a variação no teor de matéria seca da planta em diferentes estádios de linha de leite no grão de milho, concluíram que o estádio de linha de leite do grão e o teor de matéria seca na planta inteira foram positivamente correlacionados. Segundo eles, a linha de leite foi um bom indicador da época ideal de colheita do milho para silagem.

Estudando épocas de colheita, Vilela (1983) verificou que a ensilagem de milho deve ocorrer de 102 a 119 dias após a semeadura, época em que se tem de 28 a $35 \%$ de matéria seca, correspondendo ao ponto denominado farináceo duro ou pós-farináceo dos grãos.

Objetivou-se, nesse trabalho, verificar o efeito do atraso na época de semeadura e de corte de plantas para ensilagem em características agronômicas de cultivares de milho, e também avaliar o desempenho de cultivares para a produção de silagem.

\section{MATERIAL E MÉTODOS}

Os experimentos de campo foram conduzidos durante o ano agrícola de 1999/2000, em área experimental do Departamento de Agricultura (DAG), no campus da Universidade Federal de Lavras. Os experimentos foram realizados em solo classificado como Latossolo VermelhoEscuro (LE), textura argilosa e declividade de $9 \%$.

Foi avaliado o desempenho de nove cultivares de milho (AG 1051, AG 4051, AG 5011, C 435, C 505, D 657, P 3041, TORK e UFLA 2004) de diferentes bases genéticas, ciclos, tipos de grãos. O delineamento experimental empregado foi o de blocos ao acaso, com quatro repetições. A parcela experimental foi constituída de 4 linhas de 5,0 metros de comprimento, espaçadas de $80 \mathrm{~cm}$, com uma densidade de 55 mil plantas/ha.

Foram conduzidos quatro experimentos, em duas épocas distintas, novembro e dezembro. A primeira época de semeadura foi realizada no dia 16 de novembro e a segunda ocorreu em 17 de dezembro de 1999. Por época, foram conduzidos dois experimentos, e em um deles, as plantas foram cortadas quando a linha de leite atingiu a metade do grão, ou seja, quando a maioria das

Ciênc. agrotec., Lavras. V.27, n.2, p.271-277, mar./abr., 2003 
plantas da cultivar estivesse com os grãos da espiga no estádio denominado farináceo-duro, com a porcentagem de matéria seca entre 30 e $40 \%$. No outro experimento, a colheita foi realizada quando os grãos da maioria das plantas da cultivar atingiram a maturidade fisiológica.

Foram utilizados como adubação de semeadura $400 \mathrm{~kg} / \mathrm{ha}$ da fórmula $08-28-16$ com $0,5 \%$ de zinco. A primeira adubação de cobertura foi realizada com uréia (60 kg N/ha) e cloreto de potássio (50 kg $\mathrm{K}_{2} \mathrm{O} / \mathrm{ha}$ ), quando as plantas atingiram entre quatro e cinco folhas. A segunda adubação de cobertura foi realizada quando as plantas atingiram entre oito e nove folhas, utilizandose sulfato de amônio (60 kg N/ha).

Uma amostra de dez plantas selecionadas ao acaso na área útil de cada parcela foi cortada, agrupada, identificada e conduzida até o laboratório, onde foram separadas as espigas (grãos com sabugos e brácteas) do resto da planta (folhas e colmos).

As duas frações foram pesadas separadamente e picadas em pedaços com aproximadamente $2,5 \mathrm{~cm}$ de comprimento, com a finalidade de facilitar a homogeneização. Depois de bem-homogeneizada, foi retirada uma amostra de cada parte, a qual foi pesada e seca em estufa com ar forçado a $55^{\circ} \mathrm{C}$, até a obtenção de peso constante, sendo determinado o peso das frações da planta com base na matéria seca. Com esse resultado, foi calculada a participação dessas frações (espigas, colmos e folhas) na matéria seca total da planta.

As demais plantas da parcela foram trituradas em picadeira e homogeneizadas. Uma amostra de 900 gramas também foi seca em estufa com ventilação forçada a uma temperatura de $55^{\circ} \mathrm{C}$, até obtenção de peso constante e, posteriormente, foi moída em moinho tipo Willey, com peneira de $1 \mathrm{~mm}$, para a determinação do teor de matéria seca (AACC, 1976).

As seguintes características agronômicas foram avaliadas: altura de plantas, produtividade de matéria seca total $(\mathrm{kg} / \mathrm{ha})$, rendimento de grãos $(\mathrm{kg} / \mathrm{ha})$, porcentagem de espigas, folhas e colmo na matéria seca total. Com exceção dos dados de rendimento de grãos, que foi obtido nas duas linhas da bordadura da parcela, os outros caracteres foram obtidos nas duas linhas centrais da parcela.

Os dados obtidos foram submetidos inicialmente a uma análise de variância individual. Posteriormente, foi realizada uma análise da variância conjunta envolvendo as duas épocas de semeadura e as duas épocas de corte das plantas.
Todas as análises de variância e testes de média (Teste de F e Scott Knott a 5\% de probabilidade) foram realizados utilizando o programa SISVAR ${ }^{\circledR}$ (Ferreira, 1999).

\section{RESULTADOS E DISCUSSÃO}

A análise da variância conjunta envolvendo as duas épocas de semeadura e as duas épocas de corte simultaneamente, para todos os caracteres, resultou na estimativa da precisão experimental inferior a $12 \%$, sendo essa adequada ao tipo de estudo. Constatou-se efeito significativo $(\mathrm{P} \leq 0,05)$ para as épocas de semeadura e cultivares, para todos os caracteres avaliados.

Para a fonte de variação época de corte e para a interação época de corte $\mathrm{x}$ cultivares, apenas não foi observada significância para a altura de plantas, o que era de se esperar, uma vez que a altura da planta de milho é máxima, por ocasião do florescimento, permanecendo a mesma após esse estádio. Para a interação épocas de semeadura $\mathrm{x}$ épocas de corte, não foram observados efeito significativo para a produtividade de grãos, porcentagem de espigas na matéria seca e porcentagem de colmo e folhas na matéria seca total. Porém, para a interação épocas de semeadura $\mathrm{x}$ cultivares, foi observada significância para a produção de grãos. Com relação à interação tripla, foi observada significância somente para a produção de matéria seca por hectare.

Foi verificado que a produtividade de grãos foi influenciada pela época de semeadura, e a produtividade foi maior na semeadura realizada em novembro (Tabela 1). Esses resultados corroboram com os obtidos por Souza (1989), que constatou uma redução na produção de grãos de 16 a $38 \mathrm{~kg} / \mathrm{ha}$ para cada dia de atraso na semeadura, a partir do dia 15 de outubro.

Devido à presença da interação épocas de semeadura x cultivares, o comportamento das cultivares não foi coincidente nas duas épocas de semeadura. A média de produtividade das cultivares foi maior na semeadura realizada em novembro, e a cultivar AG 4051 foi a mais produtiva nas duas épocas de semeadura. Na semeadura de dezembro, também merece destaque a produtividade da cultivar AG 1051, de $8770 \mathrm{~kg} / \mathrm{ha}$ (Tabela 1).

Foi observada para a altura de plantas uma variação de 1,94 m para a cultivar AG 5011 a 2,49 m para a cultivar AG 4051, e essa cultivar apresentou na média das duas épocas de semeadura e colheita $33 \mathrm{~cm}$ mais alto que a média das demais cultivares (Tabela 2). Vale ressaltar que essa característica foi altamente influenciada pela constituição genética do material e pelas condições climáticas, o que proporcionou a grande variação observada. 
TABELA 1 - Valores médios para a produtividade de grãos (PG) de nove cultivares de milho avaliadas em duas épocas de corte das plantas. UFLA, Lavras-MG, $2001^{1}$.

\begin{tabular}{|c|c|c|c|c|}
\hline \multicolumn{5}{|c|}{ Semeadura } \\
\hline \multirow{2}{*}{ Cultivar } & Novembro & Dezembro & \multirow{2}{*}{\multicolumn{2}{|c|}{ Média }} \\
\hline & \multicolumn{2}{|c|}{ PG (kg/ha) } & & \\
\hline AG 1051 & $9127 \mathrm{~b}$ & $8770 \mathrm{a}$ & 8949 & $b$ \\
\hline C 505 & 8491 b & $6457 \quad c$ & 7474 & $\mathrm{~d}$ \\
\hline UFLA 2004 & $8063 \mathrm{c}$ & $7762 \mathrm{~b}$ & 7913 & $\mathrm{c}$ \\
\hline TORK & $9285 \mathrm{~b}$ & $7707 \mathrm{~b}$ & 8496 & $\mathrm{c}$ \\
\hline D 657 & $8351 \mathrm{~b}$ & $6304 \quad c$ & 7328 & d \\
\hline AG 5011 & $7199 \mathrm{c}$ & $7098 \quad \mathrm{c}$ & 7149 & $\mathrm{~d}$ \\
\hline P 3041 & $8970 \quad b$ & $6615 \quad c$ & 7793 & $\mathrm{c}$ \\
\hline C 435 & $8617 \quad b$ & $8124 \mathrm{~b}$ & 8370 & $\mathrm{c}$ \\
\hline AG 4051 & $11353 \mathrm{a}$ & $9492 \mathrm{a}$ & $10423 \mathrm{a}$ & \\
\hline Média & $8828 \mathrm{~A}$ & 7606 B & 8210 & \\
\hline
\end{tabular}

${ }^{1}$ Médias seguidas pela mesma letra minúscula na coluna pertencem ao mesmo agrupamento, de acordo com o teste de Scott-Knott, a $5 \%$ de probabilidade. Na linha, médias seguidas com a mesma letra maiúscula não diferem entre si pelo teste de $\mathrm{F}$, a $5 \%$ de probabilidade.

TABELA 2 - Valores médios para a altura de planta (AP) de nove cultivares de milho, considerando as duas épocas de semeadura e as duas épocas de corte das plantas. UFLA, Lavras-MG, $2001^{1}$.

\begin{tabular}{cl}
\hline Cultivar & $\begin{array}{c}\text { AP (m) } \\
\text { Média }\end{array}$ \\
\hline AG 1051 & $2,39 \mathrm{~b}$ \\
C 505 & $2,22 \quad \mathrm{~d}$ \\
UFLA 2004 & $2,21 \quad \mathrm{~d}$ \\
TORK & $2,00 \quad \mathrm{f}$ \\
D 657 & $2,09 \quad \mathrm{e}$ \\
AG 5011 & $1,94 \quad \mathrm{f}$ \\
P 3041 & $2,19 \quad \mathrm{~d}$ \\
C 435 & $2,30 \quad \mathrm{c}$ \\
AG 4051 & $2,49 \mathrm{a}$ \\
\hline Média & 2,20 \\
\hline
\end{tabular}

${ }^{1}$ Médias seguidas pela mesma letra na coluna pertencem ao mesmo agrupamento, de acordo com o teste de Scott-Knott, a $5 \%$ de probabilidade.
Verificou-se que a altura de plantas foi influenciada pela época de semeadura, e as cultivares apresentaram um maior porte na semeadura realizada em novembro (Tabela 3). Resultados semelhantes foram encontrados por Ramalho (1999), que constatou um decréscimo médio diário de $1,0 \mathrm{~cm}$ na altura da planta com o atraso da semeadura.

Apesar da existência da interação épocas de semeadura $\mathrm{x}$ época de corte, foi observado para as duas épocas de semeadura que os tipos de corte realizados não influenciaram a altura da planta (Tabela 3 ). Esses resultados eram esperados, uma vez que a altura da planta de milho é máxima, por ocasião do florescimento, permanecendo a mesma após esse estádio. Porém, independente da época de realização do corte das plantas, as cultivares semeadas em novembro apresentaram altura de planta superior àquelas semeadas em dezembro.

Para a produtividade de matéria seca, as cultivares AG 1051, C 435 e AG 4051 produziram nas duas épocas de semeadura e corte das plantas, em média, $2.050 \mathrm{~kg} / \mathrm{ha}$ a mais que as demais cultivares (Tabela 4). Os resultados de produtividade de matéria seca das cultivares estão de acordo com o que é comumente observado em outros trabalhos, nos quais têm sido constatado valores de produtividade de matéria seca variando de 
$8.000 \mathrm{~kg} / \mathrm{ha}$ a $23.000 \mathrm{~kg} / \mathrm{ha}$, conforme obtidos por Fonseca (2000) e Melo et al. (1999).

TABELA 3 - Valores médios para a altura de planta (AP), considerando as duas épocas de semeadura e as duas épocas de corte das plantas. UFLA, Lavras-MG, $2001^{1}$.

\begin{tabular}{lcc}
\hline \multirow{2}{*}{ Corte } & \multicolumn{3}{c}{ Semeadura } \\
\cline { 2 - 3 } & Novembro & Dezembro \\
\hline Meia linha de leite & 2,33 a A & 2,06 a B \\
Matur. fisiológica & 2,30 a A & 2,11 a B \\
\hline Média & $2,31 \quad \mathrm{~A}$ & $2,08 \quad \mathrm{~B}$ \\
\hline
\end{tabular}

${ }^{1}$ Médias seguidas pela mesma letra minúscula na coluna e maiúscula na linha não diferem entre si pelo teste de $\mathrm{F}$ a $5 \%$ de probabilidade.

TABELA 4 - Valores médios para a produtividade de matéria seca (PMS), porcentagem de espiga na matéria seca (\% EMS) e porcentagem de colmo e folhas na matéria seca (\% CMS) de nove cultivares de milho, considerando as duas épocas de semeadura e as duas épocas de corte das plantas. UFLA, Lavras-MG, $2001^{1}$.

\begin{tabular}{lcccc}
\hline \multicolumn{1}{c}{ Cultivar } & PMS (kg/ha) & \% EMS & \% CMS \\
\hline AG 1051 & $18450 \mathrm{a}$ & $67,19 \mathrm{~b}$ & $32,80 \mathrm{a}$ \\
C 505 & $16002 \mathrm{~b}$ & $68,71 \mathrm{a}$ & $31,28 \mathrm{~b}$ \\
UFLA 2004 & $15729 \mathrm{~b}$ & $67,95 \mathrm{a}$ & $32,04 \mathrm{~b}$ \\
TORK & $16236 \mathrm{~b}$ & $68,75 \mathrm{a}$ & $31,24 \mathrm{~b}$ \\
D 657 & $16102 \mathrm{~b}$ & $67,84 \mathrm{a}$ & $32,15 \mathrm{~b}$ \\
AG 5011 & $15559 \mathrm{~b}$ & $68,19 \mathrm{a}$ & $31,80 \mathrm{~b}$ \\
P 3041 & $15632 \mathrm{~b}$ & $69,19 \mathrm{a}$ & $30,80 \mathrm{~b}$ \\
C 435 & $17796 \mathrm{a}$ & $68,79 \mathrm{a}$ & $31,20 \mathrm{~b}$ \\
AG 4051 & $17534 \mathrm{a}$ & $66,18 \mathrm{~b}$ & $33,81 \mathrm{a}$ \\
\hline Média & 16560 & 68,09 & 31,90 \\
\hline
\end{tabular}

${ }^{1}$ Médias seguidas pela mesma letra minúscula na coluna pertencem ao mesmo agrupamento, de acordo com o teste de Scott-Knott, a $5 \%$ de probabilidade.
Para a participação da espiga na matéria seca, foi observada uma variação de $66,18 \%$ para a cultivar AG 4051 a 69,19 \% (P 3041). Esses resultados são considerados altos, se se levar em consideração que, de uma maneira geral, no Brasil, a variação na participação das espigas na matéria seca está entre $25 \%$ e $57 \%$ (Fonseca, 2000). Porém, ao se considerar que a elevada participação da espiga na matéria seca é uma importante característica para a obtenção de silagem de boa qualidade, esses resultados foram extremamente satisfatórios.

A participação da fração colmo e folhas na matéria seca, como esperado, por ser o complemento da outra fração, foi pequena, com variação de 30,80 \% '(P 3041)' a 33,81 \% '(AG 4051)'. Assim, quanto menor a participação da fração colmo e folhas na matéria seca total, maior será a participação da espiga na matéria seca, o que poderá proporcionar melhor qualidade de silagem.

Geralmente, as cultivares que produzem mais grãos são também recomendadas para a produção de silagem. Entretanto, existem vários relatos na literatura que mostram que as melhores cultivares para a produção de grãos nem sempre são as indicadas para a produção de silagem de qualidade (Carter et al., 1991).

A maior produtividade de matéria seca é uma característica altamente desejável para as cultivares destinadas para a produção de silagem, pois está diretamente relacionada com a redução no custo de produção da tonelada de silagem. Neste trabalho foi verificado que a produtividade de matéria seca foi influenciada pela época de semeadura e de corte das plantas (Tabela 5). A produtividade de matéria seca foi superior no corte realizado com os grãos na maturidade fisiológica e com a semeadura realizada em novembro. Com relação à época de semeadura, os resultados obtidos estão de acordo com os relatados por Keplin \& Santos (1996), que também verificaram uma redução na produção de matéria seca em decorrência de uma semeadura mais tardia.

Apesar da maior produtividade de matéria seca na colheita realizada com os grãos na maturidade fisiológica, sabe-se que a qualidade dessa silagem é inferior, em relação a quando as plantas são colhidas com os grãos na meia linha de leite, estádio preconizado como ideal para colheita das plantas para ensilagem (Coors et al., 1994).

A maior produtividade de matéria seca para a semeadura realizada em novembro provavelmente se deva à ocorrência de condições climáticas mais favoráveis à cultura, principalmente em relação à distribuição de chuva e à variação de temperatura. Vale ressaltar que na região sul de Minas Gerais vários agricultores têm postergado a semeadura até janeiro, principalmente para a produção de silagem, o que tem acarretado redução 
significativa no crescimento da planta, refletindo na redução da produtividade e qualidade da forragem.

TABELA 5 - Valores médios para a produção de matéria seca (PMS), considerando as duas épocas de semeadura e as duas épocas de corte das plantas. UFLA, Lavras-MG, $2001^{1}$.

\begin{tabular}{|c|c|c|c|}
\hline \multirow{3}{*}{ Corte } & \multicolumn{3}{|c|}{ Semeadura } \\
\hline & Novembro & Dezembro & \\
\hline & \multicolumn{2}{|c|}{ PMS (kg/ha) } & \\
\hline Meia linha de leite & $16951 \mathrm{~A} \mathrm{~b}$ & $14346 \mathrm{~B} \mathrm{~b}$ & $15648 \mathrm{~b}$ \\
\hline Matur. Fisiológica & $19362 \mathrm{~A} \mathrm{a}$ & $15582 \mathrm{~B}$ a & $17472 \mathrm{a}$ \\
\hline Média & $18156 \mathrm{~A}$ & 14964 B & 16560 \\
\hline
\end{tabular}

${ }^{1}$ Médias seguidas pela mesma letra minúscula na coluna e maiúscula na linha não diferem entre sí pelo teste de $\mathrm{F}$ a $5 \%$ de probabilidade.

Na tabela 6 , observa-se que a porcentagem de espigas e da fração colmo e folhas na matéria seca foram influenciadas pela época de semeadura e de corte das plantas. A participação da espiga na matéria seca foi superior no corte realizado com os grãos na maturidade fisiológica e com a semeadura realizada em novembro. Obviamente, para a participação da fração colmo e folhas ocorreu o inverso.

Keplin \& Santos (1996) verificaram, com o atraso na época de semeadura, uma redução na porcentagem de espigas e um aumento na contribuição do colmo na matéria seca, o que corrobora com os resultados obtidos neste trabalho.

TABELA 6 - Valores médios para a porcentagem de espiga na matéria seca (\% EMS) e porcentagem de colmo e folhas na matéria seca (\% CMS) em relação à época de semeadura e época de corte das plantas. UFLA, Lavras-MG, $2001^{1}$.

\begin{tabular}{cll}
\hline & \% EMS & \% CMS \\
\hline Semeadura: Novembro & $68,97 \mathrm{a}$ & $31,02 \mathrm{~b}$ \\
Dezembro & $67,21 \mathrm{~b}$ & $32,78 \mathrm{a}$ \\
\hline Corte: Meia linha de leite & $67,66 \mathrm{~b}$ & $32,33 \mathrm{a}$ \\
Matur.fisiológica & $68,51 \mathrm{a}$ & $31,48 \mathrm{~b}$ \\
\hline
\end{tabular}

${ }^{1}$ Médias seguidas pela mesma letra minúscula na coluna para as épocas de semeadura e de corte das plantas não diferem entre si pelo teste de $\mathrm{F}$ a $5 \%$ de probabilidade.

\section{CONCLUSÕES}

As cultivares AG 1051, C 435 e AG 4051 são as mais adequadas à produção de silagem;

A maioria das características avaliadas foi influenciada pela época de semeadura e de corte das plantas, evidenciando a importância da escolha da cultivar para produção de silagem em função destes fatores;

$\mathrm{O}$ atraso na semeadura reduz, significativamente, a produção de matéria seca de silagem e a produtividade de grãos.

\section{REFERÊNCIAS BIBLIOGRÁFICAS}

AMERICAN ASSOCIATION OF CEREAL CHEMISTS. A.A.C.C. Approved methods of the American Association of Cereal Chemists. 7. ed. Saint Paul, 1976. 256 p.

CARTER, P. R.; COORS, J. G.; UNDERSANDER, D. S.; ALBRECHT, K. A.; SHAVER, R. D. Corn hybrids for silage: na update. In: ANNUAL CORN AND SORGHUM RESEARCH CONFERENCE, 46., 1991, Washington. Proceedings... Washington: [s.n.], 1991. p. 141-164.

COORS, J. G.; CARTER, P. R.; HUNTER, R. B. Silage corn. In: HALLAUER, A. R. (Ed.). Specialty Corns. Ames: CRC, 1994. cap. 11, p. 305-340.

FERREIRA, D. F. SISVAR - Sistema de Análise de Variância: versão 3.04. Lavras, 1999. Sisvar, 1 disquete, $3 \frac{1}{2}$ pol.

FONSECA, A. H. Características químicas e agronômicas associadas à degradabilidade da silagem de milho. 2000. 93 p. Dissertação (Mestrado em Fitotecnia) - Universidade Federal de Lavras, Lavras.

GONÇALVES, G. A.; RAMALHO, M. A. P.; RIBEIRO, P. H. E.; MARQUES JÚNIOR, O. G. Seleção de famílias de meio irmãos de milho em três épocas de semeadura visando produção de silagem. Brazilian Journal of Genetics, Caxambu, v. 19, n. 3, p. 218, set. 1996.

KEPLIN, L. A. S.; SANTOS, I. R. Silagem de milho. [S.1.]: Braskalb Agropecuária Brasileira, 1996. 46 p.

MELO, W. M. C.; VON PINHO, R. G.; VON PINHO, E. V. R.; CARVALHO, M. L. M.; FONSECA, A. H. Parcelamento da adubação nitrogenada sobre o desempenho de cultivares de milho para produção de silagem. 
Ciência e Agrotecnologia, Lavras, v. 23, n. 3, p. 608616, jul./set. 1999.

OLIVEIRA, M.D.X.; SANTOS, M.X.; RAMALHO, M. A.P. Rendimento de grãos de três cultivares de milho (Zea mays L.) de diferentes ciclos, em diversas épocas de semeadura, em duas localidades do Estado de Mato Grosso do Sul. Ciência e Prática, Lavras, v.15, n.3, p.287-294, 1991.

RAMAlHO, A. R. Comportamento de famílias de meio-irmãos em diferentes épocas de semeadura visando à produção de forragem de milho. 1999. 78 p Dissertação (Mestrado em Fitotecnia) - Universidade Federal de Lavras, Lavras.
SOUZA, S. N. Milho para silagem: considerações agronômicas. Agropecuária Catarinense, Florianópolis, v. 2, n. 2, p. 11-14, jun. 1989.

SULC, R. M.; THOMISON, P. R.; WEISS, W. P. Reliability of the Kernel milkline method for timing corn silage harvest in Ohio. Journal of Production Agriculture, Columbus, v. 9, n. 3, p. 376-381, 1996.

VILELA, D. Silagem. Informe Agropecuário, Belo Horizonte, v. 9, n. 108, p. 17-27, 1983. 